\title{
Differentiating Instructions to Teach English Reading Comprehension for Mathematics Department Students
}

\author{
Emma Rosana Febriyanti, Elvina Arapah \\ English Departement, Faculty of Teacher Training and Education \\ Universitas Lambung Mangkurat \\ Banjarmasin, Indonesia \\ emmafebri@yahoo.com, elvteen1327@gmail.com
}

\begin{abstract}
Many approaches, strategies, or techniques can be chosen by teachers to deliver their teaching materials. However, not all can be applied in a class especially if the students are coming from various backgrounds, have mixed ability and are at different levels of proficiency. Therefore, the teachers have to determine which that gives most benefits for their students. Mathematics department students who received English subject as one of the compulsory courses may feel difficulties in comprehending English reading materials since English is not their major. Consequently, by understanding all differences, differentiating instructions is necessary to be done for achieving the success in teaching and learning activities. This research is aimed at describing what and how differentiated instruction is done in the classroom to teach English reading comprehension about wetlands. It is expected that the results will give better insights for the teachers as well as the students about the best strategy to teach reading comprehension that can cope with large classes and various needs of the students in teaching and learning English for science students. The findings suggest that differentiated instruction is challenging because the major of the students can determine the tasks that they choose. The differentiated instruction needs more preparation from the teachers because there must be considerations on the students' level of readiness, interest, and learning profile.
\end{abstract}

Keywords-differentiated instruction; english materials; reading comprehension; wetland materials; mathematics department

\section{INTRODUCTION}

Teaching English as a foreign language in Indonesia is quite a challenging task, especially teaching English to students who are not majoring English in their study. Students in all departments of FKIP, Lambung Mangkurat University Banjarmasin and the second or third semester of their study must take English subject as part of the requirements. In the context of higher education or university, the students who are taking English course are not questioned about the reasons why they want to learn English, but it is because they must take this course whether they like or dislike it. In this case, the English subject taken by students in university level can be called as English for Specific Purposes (ESP) as this subject is given to accomplish the specific needs of the learners: academic or workplace tasks. However, this can be a problem for many teachers since they have to deal with different English proficiencies of their students. Therefore, choosing the best strategy that can manage the whole thing is becoming very urgent for all teachers of English course.

Referring to university policy, that is to enable ULM to become the center of Asia-Pacific wetlands development in 2027, it is necessary that all students in this university have better English proficiency and have decent knowledge about wetlands itself. However, most of them are in a lower intermediate level, and this has led ESP teachers to work harder to improve their students' skills to attain ESP goals. Also, the motivation of students in learning English is not too high so that their ability cannot be increased significantly. Due to the difficulties in learning English, the students might easily lose their interest.

The students who are attending the English course have mixed-competence and different abilities in the English language. However, they are put in one class to receive the same dominated one-size-fits-all language instruction though they have different learning styles and preferences. This type of classroom, without proper ways of handling, may bring both serious consequences on teaching and learning process for the students, instructors, even the institutions. For students, studying in a classroom composed of classmates with different competence levels may affect their learning process, including their motivation in learning and classroom participation. Eventually, this may impact their progress during the course as well as final achievement. For the teachers, teaching in a mixed-competence class may lead to confusion on finding the midpoint from which to teach.

As a consequence, the teacher may fail to help students achieve the learning goals. When learning goals are not achieved, and students fail the course, the institution is consequently faced with a problematic issue of successfully educating its students/candidates. Therefore, teachers have to deal with challenges to anticipate and minimize the possible problems occurred. The using of numerous materials and strategies gives many benefits for the teachers as well as the students. Therefore, differentiating instruction as a strategy to teach different students' needs are necessary to be applied in this kind of class. 


\section{LITERATURE REVIEW}

Every individual is different, and this also applies to the students who come into our class. They have different ways on how they proceed information and expressing what they learn; some may easily comprehend the information, and some may need more time to think about it, some are gifted and some are average, or some may need friends to help to understand and some like to work alone. Reference [1] mentions some significant differences existing among the students, such as differences in the level of knowledge, skills, experiences, and habits; differences in cognitive capabilities and processes of cognition; differences in interests; and differences in the pace of learning, motivation for learning and student's development. Based on these differences, instructions should be students' centered, varied and different for each student as to give multiple options in absorbing the information and making sense of ideas. Differentiate instruction means to recognize those differences concerning individual and diverse students in the same classroom so that individual student can learn effectively. Reference [2] mentions that this strategy requires teachers to be flexible in their approach to teaching and adjust the curriculum and presentation of information to learners rather than expecting students to modify themselves for the curriculum.

Differentiated instruction is a compilation of many educational theories and practices that support the maximization of student learning for all students in the same class and help them to experience success [3]. Several studies demonstrated the positive effects of differentiated instruction on students such as students' positive motivation in learning, an increased level of students' involvement and engagement in a task solving, and creativity in learning process, and a better collaboration with their peers. This also helps students make the connection with what is being taught in the classroom to the things they value outside of class; therefore, students can make their learning becomes more meaningful [4].

English subject can be difficult and painful for Mathematics department students since they are not majoring in it. Once the students' achievement in learning English are having significant difference, it is the job of the teachers to do something as to differentiate instruction to make the teaching and learning more successful [1]. Further, regarding English reading instruction, reference [5], and reference [6] suggest the teachers to differentiate instruction since the average and low achieving students cannot take advantage of the class, while high achieving students make the highest gain since they are exposed to more text at a faster pace. In other words, successful readers continue to improve themselves while the struggling readers stay behind. Additionally, in non-differentiated classrooms where the students receive the same activities, the same materials and assignments, the teacher often abandons the high ability or low ability students and gives focus on the average learners only. Reference [1] argues if the students are taught using the same instruction, they would interact less in class, ask for teacher's assistance more frequently, and would undergo more frustration and confusion in doing class activities. However, having a class in which the teacher can differentiate instruction is quite rare and difficult to do if the teacher does not retain a deep knowledge of the reading process and understand how to teach differently and responsively.

In describing differentiated instruction, it is better to mention what differentiated instruction is to clear away some confusions [1], [7]. First, differentiated instruction is proactive which means that the teacher should proactively plans a variety of ways to get into students' diverse needs, in contrast with planning a single approach for everyone in the classroom. Second, differentiated instruction is more qualitative than quantitative. It is not about the number or quantity of assignments got by advanced students while others got less, but it is about adjusting the nature of the assignment to meet the students' needs as well. Next, differentiated instruction is rooted in assessment which means the teacher should provide alternatives to assess and determine the most suitable way for students to demonstrate or share what they have learned. Fourth, differentiated instruction is provides multiple approaches to content, process, and product. There three things suggest teachers to apply different approaches about what students learn, how they best learn it, and how they exhibit what they've learned. Fifth, differentiated instruction is organic. Learning experiences are best happen when they engaging, relevant, interesting, and challenging which means students are asked to decide on their own and take responsibility. Finally, differentiated instruction is a combination of whole-class, group, and individual instruction. Here, the instruction is done by students coming together as a whole group, then they move to do activities individually or small groups. After that, they may go back together as a class to discuss, share or review, then moving out again to do more work in small groups or individually, and so on.

Teachers should pay attention to students' differences since they shape the content of instruction. Students' variances can be seen in three areas, namely student's level of readiness, interests, and learning profiles [1]. The concept of readiness constructs students' knowledge and understanding that are shaped by prior learning and life experiences, attitudes, and proficiency. About students' level of readiness, teachers should provide students with tasks within each student's zone of proximal development (ZPD). Zone of proximal development is a term used by reference [1] to describe the "distance between the actual development level as determined by independent problem solving and the level of potential development as determined through problem solving under adult guidance or in collaboration with more capable peers." This term denotes that one student only cannot contribute alone, but he/she can do well if provided with support or scaffolding from the teacher or other students. Instruction within ZPD allows new learning to take place since the students can access new information or do tasks that are beyond their level but within they reach. In this relation, the theory of readiness suggests that tasks should always "be in advance" of a student's current level of mastery. It means that if the tasks is presented below or at student's mastery level, there will be no improvement. On the contrary, if the tasks are above the level, the student will be frustrated and confused [1]. Hence, the goal of differentiation to ensure all students are provided with appropriately challenging learning experiences [8-9]. 
Students also varied in term of interest. Therefore, giving students options at every step of their learning and addressing them based on their interest in learning are important to do. Since interest and motivation are interrelated, modifying instruction is more likely to enhance students' motivation as well as their productivity and achievement to engage in the classroom tasks. For example, when students are encouraged to select reading material of interest to them, they are more likely to carry out better engagement and better results [9]. Reference [4] suggest some ways to have successful differentiated instruction, such as giving students the opportunity to focus on their preferred interests, utilizing examples that relate to students' experiences and focusing content on student-driven topics and inquiry. In conclusion, determining and designing different tasks that fit into students' interest will lead to positive learning behavior in both short and long term. Also, differentiation can also encourage students to discover their new interests [10].

Besides responding to students' readiness level and interests, teacher should also think about students' differences in learning profile. This learning profile refers to students' preferences of learning that are affected by learning style, intelligence preference or thinking style, gender and culture [9]. Students are different in the way they want to learn, how they absorb and think new ideas and the setting where they are from which influence their accomplishment in learning. Teachers who apply differentiate instruction consider that every student is unique with their divergent learning styles and preferences [11. Regardless of their students' learning profile differences, they still can benefit from numerous and varied exposure to the same concept. Therefore, to make adequate and effective instruction that provides options to all students learning profile preferences appears to be very essential as the students will make benefit of it. Similarly, differentiation guided by learning profiles allows students to learn by means that are natural and efficient [10-11].

After understanding how students are different from one another, teachers may choose to differentiate the content, product, and process of their instruction concerning students' level of readiness, interests, and their learning profile [2]. The differentiation in the term of content means differentiating what students learn, that is how students proceed and develop their understanding of concept being taught. Meanwhile, in the term of process, the teacher distinguishes activities or materials based on how students participate best in learning. The last is product which means the teacher differentiates assessment or medium for the students to demonstrate what they know and are capable of doing as the conclusion of the lesson or unit.

Some studies have witnessed the effectiveness of differentiated instruction in primary and secondary schools, but this strategy has limited number of publication in the higher education level. In higher education, instruction is dominated by one-size-fits-all pedagogical method, which insufficiently attends a diverse student body [12]. This due to some problems related to the lack application of differentiated instruction in college level as mentioned by reference [4], [12-13], First, it refers to the large sizes of class which reference [4] defines a large class as a classroom setting which has 50 to 500 students. Teachers in university sometimes experience teaching one course consists of more than 100 students. Teaching with this number of students is challenging and demanding at the same time, and it also takes all energy of the teacher.

Consequently, the teacher prefers of using one or the same instruction that fits to all students in the classroom rather than using differentiated instruction. Second, teachers in university level have minimal contact time with the students, and seldom have they own classroom.

Moreover, they meet the students once in a week and even worst, they cannot remember some of the students' names. Hence, teachers may be limited in how much they can modify classroom instruction to meet all students' needs. Third, teachers in university have limited time to create multiple means of students' assessment since they must write research and do service obligations. Next is controversy over ethical issues such as fairness in grading. If the students feel their grade unsatisfactory resulting from unfair task or instruction given by their teacher, they will feel irritated and become unmotivated in learning. This unexpected result makes the teacher often use the same instruction for whole class students. However, reference [14] found that there is a problem associated with the presence of a high percentage of students repeating one course. This can be said as an indication that traditional methods cause a mismatch between instruction and students' academic needs.

Although differentiated instruction has both strengths and limitations, this strategy embraces a comprehensive range of teaching strategies and approaches. This strategy needs to be implemented so that the students in higher level can achieve a greater level of individual growth and academic success in their education. Among the few studies within higher education, findings testify differentiated instruction gives benefits for both teachers and students. Reference [10] conducted a study for postsecondary students using differentiated instructional strategies such as flexible groupings, interest-based centers, independent study projects, tiered assignments, flexible timelines, supplemental readings, and reading comprehension support. They found that differentiated had a positive and meaningful impact on students' leaning. They also found that differentiation was beneficial for college students since they have diverse ways of learning, diverse interests, experiences, and goals as well as diverse personal circumstances.

Another study conducted in college level is done by reference [13]. They examined the impact of differentiated instruction in an undergraduate first-year math course at two universities by using qualitative and quantitative methods. The results of the study provide suggestions for teachers to do or prepare before implementing the instruction and offer evidence about the effectiveness of differentiated instruction in enhancing students' mathematical understanding.

Reference [14] also conducted an experimental study for 41 Foreign Language pre-service teachers and 53 Mathematics pre-service teachers from a Romanian college. She investigated the intervention of differentiated instruction compared with two dependent variables: intrinsic motivation and academic achievement. Then, it was found that there were significant increases on pre and post-test achievement scores within subjects for the experimental group under the aspect of intrinsic 
motivation, and no differences for the control group. However, it was also found that there were no statistically significant differences in term of academic achievement obtained by experimental group and the control group.

The last is an analytical study from reference [4]. They investigated 20 instructors across disciplines who experience teaching large classes in university level. The participants were asked to answer four research questions: how they define differentiated instruction, to what level they use differentiated instruction to teach large classes, their perception about the use of differentiated instruction, and how they describe the benefits and challenges of differentiated instruction. The results indicate that differentiated instruction is more challenging and difficult especially when applied in large classes, though newer teaching strategies that suitable with differentiated instruction are introduced and can be incorporated. However, every participant in the study agreed that differentiated instruction has beneficial benefits for students in higher level.

\section{METHOD}

The participants under this study were the third semester of pre-service teachers from Mathematics department in Lambung Mangkurat University Banjarmasin. There were 20 students (3 male and 17 female) ranging in age from eighteen to nineteen involved in the study, and they can be called as ESP students since they learn English for specific purposes. The students associated to have different level of readiness in learning English, interest, and learning profile which lead to significant implications for course content, processes, and products.

As previously mentioned, English is introduced to all departments in the university as a course subject that must be taken by them. Reading skill becomes the most taught in the class since they are expected to have good ability to read materials related to their major in English. The topic chosen for the reading is about wetlands.

\section{RESULT AND DISCUSSION}

There are many points to consider and prepare when a teacher decided to have differentiated reading instruction in the classroom. Reference [5] mention some points that a teacher must ponder; they are assessment, grouping formats, classroom management, materials, length and frequency of instruction, and the lesson focus. Meanwhile, reference [10] state that the teacher needed first to identify a set of clear course objectives that students are expected to demonstrate by the end of the semester. However, due to some constraints, the teacher only implemented the teaching reading by using differentiated instruction once as try-out. Below are the steps done by the teacher in applying differentiated instruction to teach English reading comprehension about wetlands for Mathematics students.

First, to introduce the topic, the teacher used whole-class instruction by asking students' background knowledge and experiences as well as showing them pictures related to wetlands. This was done to ensure all students grasp the key ideas of what they are going to learn. After getting answers from the students, teacher slightly explained what wetland is, and linked it with students' answers. Next, the teacher handed a passage about wetlands to every students and asked them to read in turn. Here, shared reading or interactive read aloud is used to provide explicit teaching through modeling for all of the students in the class. After that, the teacher asked the students about what they have understood about the passage and related it with the answers they have provided previously. Those are examples of instruction in which the teacher considered about students' level of readiness. This ensured that each student had opportunities to obtain understanding of essential information about the topic before they go further.

Then, the students are assigned into six groups consisting three students in each group and 1 group consisting of 2 students. This small group division is intended to enable students to benefit from collaborative "study group" support. The teacher provided some cue-cards containing some instructions that would be chosen by the groups to be presented in front of the class for relating the materials with students' interests, and learning profiles, The instruction they chose is the one that they can produce based on their interpretation and understanding about the passage. Some of the instructions are like asking the students to develop mime/dance, create a role-play/lip-sync/puppet show, solve a problem together, label a diagram, discover or experiment, survey or interview others, describe a sequence or process, draw a picture/create a cartoon, doodle or poster, and some others. These instructions are designed to meet students learning profiles. For example, students with kinesthetic preference will choose to develop a mime/dance or create a role-play/lip-sync/puppet show, while those who are visuals will choose to label a diagram. After the students chose the strategy, they were given 15 minutes to read the passage and to prepare a presentation based on the instruction chosen. For the presentation, each group was given 10 minutes and 3 minutes for question and answer session. After all, students presented, teacher gave the conclusion and did closing.

In term of content, the materials used this reading lesson is based on the instructional reading level of the students in the group as well as the interests of the group members as suggested by reference [4]. Additionally, the passage is accompanied with various activities so that the students can take benefit such as pre-reading questions, guided reading questions, key point summaries, and highlighted vocabulary. Tiered activities such as oral explanations with visual representations, note-taking, and Think-Pair-Share format were also used regarding to process [10]. In this study, the teacher tried to differentiate the product by giving the students various cue-cards to choose. Since the groups chose different instruction, the results were also different. Based on this, it is proven that differentiated instruction is helpful for students learning they are different regarding readiness, interest, and learning profile.

From the classroom observation, it was seen that all students engaged in throughout the lesson. During lecturing and discussion, all students were also paying attention. Although the passage was of their interest, it was quite 
difficult to understand since all written in English; however, the students are keen to look up the words they do not understand in dictionary. In groups' activity, all students in the group worked well together, and they were able to complete the task given by choosing the strategy of their own. Reference [16] mentions, "When new material or content is introduced, and the level of difficulty is higher, the teacher provides support with teacher-led modeling that clarifies meaning and engages students in discussions to enhance comprehension." Similarly, if the teacher thinks that his students are ready, he will move forward to activities which his students have interest of and then lead to independent learning. This is what differentiated instruction created for

\section{CONCLUSION}

The purpose of this study was to examine the potential use of differentiated instruction for the Mathematics college students in learning English. The result of this study can be viewed as evidence of the effectiveness of differentiated instruction to teach English reading skill in higher level of education. The study also reveals that Mathematics students tend to think logically related since they interested to do problem solving, do experiment, and describe a process, instead of to create role-play, develop a mime, or draw a picture. Therefore, it would be beneficial if the teachers try to apply differentiated instruction in their classroom suited to students' needs as well as their major. Nevertheless, as the most important point, the teacher should design and provide instruction that meet students' level of readiness, interest, and learning profile as well as differentiate their instruction in the level of content, process, and product. The results of this study support other findings related to differentiated instruction in higher education.

It should be pointed out that this study has some drawbacks. Hence, it is suggested to do further research about differentiated instruction in other departments or majors to get more validity results. Similarly, it is also important to find out teachers' and students' perceptions about the implementation of differentiated instruction, and how if it is carried out in large class. Finally, it is advisable to have differentiated instruction for the whole semester and then compare the results both quantitatively and qualitatively.

\section{REFERENCES}

[1] S. Kadum-Bošnjak, B. Buršic-Križanac, "Impact of differentiated instruction on achievement in teaching Mathematics to lower-stage grades", Metodicki obzori, vol. 15, no.7, pp. 15-29, 2012.

[2] C. A. Tomlinson, How to differentiate instruction in mixed ability classrooms 2nd ed. Alexandria: Association for Supervision and Curriculum Development, 2001.

[3] T. Hall, N. Strangman, A. Meyer, Differentiated instruction and implications for UDL implementation. Effective classroom practices report. Wakefield, MA: National Center on Accessing the General Curriculum, 2003.

[4] S. D. Turner, O. J. Solis, and D. H. Kincade, "Differentiating instruction for large classes in higher education," International Journal of Teaching and Learning in Higher Education, vol. 29, no. 3, pp. 490-500, 2017.

[5] J. W. Ankrum, R. M. Bean, "Differentiated reading instruction: what and how," Reading Horizons, vol. 48, no. 2, pp. 132-146, 2008. M. A. Cannon, "Differentiated Mathematics instruction: An action research study," Doctoral Dissertation, 2017. [Online]. Available: http://scholarcommons.sc.edu/etd/4222

[6] R. Wormeli, "Busting myths about differentiated instruction," Principal Leadership, vol. 5, no. 7, pp. 28-33, 2005.

[7] C. A. Tomlinson, C. Brighton, H. Hertberg, C. M. Callahan, T. R. Moon, K. Brimijoin, L. A. Conover, and T. Reynolds, "Differentiating instruction in response to student readiness, interest, and learning profile in academically diverse classrooms: a review of literature," Journal for the Education of the Gifted, vol. 27, no. 2, pp. 119-145, 2003.

[8] T. Santangelo, and C. A. Tomlinson, "The application of differentiated instruction in postsecondary environments: benefits, challenges, and future directions," International Journal of Teaching and Learning in Higher Education, vol. 20, no. 3, pp. 307-323, 2009.

[9] K. M. Anderson, "Tips for teaching: Differentiating instruction to include all students," Preventing School Failure, vol. 51, no. 3, pp. 4953, 2007.

[10] H. R. Ernst, T. L. Ernst, “The promise and pitfalls of differentiated instruction for undergraduate political science courses: Student and instructor impressions of an unconventional teaching strategy, "Journal of Political Science Education, vol. 1, pp. 39-59, 2005.

[11] M. Chamberlin, M. Powers, "The promise of differentiated instruction for enhancing the mathematical understandings of college students," Teaching Mathematics and Its Applications, vol. 29, pp. 113-139, 2010.

[12] M. Dosch, M. Zidon, "The course fit us: differentiated instruction in the college classroom," International Journal of Teaching and Learning in Higher Education, vol. 26, no.3, pp. 343-357, 2014.

[13] C. Tulbure, "Differentiating instruction upon learning styles in higher education: a controversial issues," Bulletin of the Transilvania University of Braşov, vol. 53, no. 1, pp. 79-84, 2011.

[14] V. Gibson, Differentiating instruction: Teaching differently to improve reading instruction. Minnesota: Read Naturally, Inc, 2011. 